\title{
Climate change and disease risk in the Himalayas
}

\author{
Climate change is likely to increase the burden of infectious diseases in the \\ Himalayas; systematic preparation must start now
}

\section{Sahotra Sarkar}

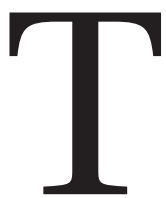

he International Centre for Integrated Mountain Development (ICIMOD, Kathmandu), with funding from the MacArthur Foundation, has recently performed a detailed analysis of the impacts of climate change on the Eastern Himalayas (Sharma et al. 2009). Their report focuses primarily on biodiversity and ecosystem services. As expected, the predictions are dire while the uncertainties remain large, given the paucity of serious attention to this region compared, for instance, to the Alps or even to the Andes. While the report notes the implications of climate change for human well-being, including health, infectious disease gets only passing mention (three paragraphs out of 25 pages). This is unfortunate because there is ample reason to expect that climate change in the Himalayas will lead to a significant increase in the regional infectious disease burden due, in particular, to vector-borne tropical diseases that have historically been absent from the Himalayas.

The reasons are simple. First, climate change is likely to lead to a deterioration of water quality, partly because the increased initial meltdown and excess in water availability will be followed by a very significant reduction in supply. Resulting shortages of good quality water will increase the burden of diarrheal disease. Even cholera may emerge as a significant problem because of its known association with climate (Colwell 1996), and given its current incidence in some parts of the Indian Himalayas and Nepal. Second, there will also be a likely decrease in air quality, with a higher concentration of pollutants such as nitrogen dioxide and airborne-particles (the latter primarily in urban areas), and an increase in lower tropospheric and ground-level ozone levels, all leading to an increased frequency of cardio-respiratory disease.

Third, and perhaps most important,

A new challenge is unfolding in the Himalayas: a significant increase in the burden of infectious disease, driven by climate change. Vectors are moving beyond their historic ranges to higher elevations; water quality is deteriorating, and the available supply is diminishing. Preventive and ameliorative measures to address these problems require robust quantitative estimates of the size and spatial distribution of disease risk. Once enough data are available, disease risk can be mapped with predictive models so that appropriate policies can be formulated and implemented. Unfortunately, there has been virtually no quantitative epidemiological attention to this region. systematic temperature increases $\left(0.01-0.04^{\circ} \mathrm{C}\right.$ per year, according to the ICIMOD scenarios) will allow tropical diseases to expand their range to higher elevations at which they did not occur before. These include a large spectrum of vector-borne (and, often, reservoir-dependent) diseases that have already begun to become problems in the region, including (visceral) leishmaniasis (locally known as kala-azar), dengue, and malaria. (The ICIMOD report also mentions schistosomiasis but it is unlikely that this disease will emerge as a major problem in the Himalayas given its very low frequency in neighboring regions.)

The possible upward spread of leishmaniasis is particularly worrisome because it has recently recently begun to be established at an altitude greater than $600 \mathrm{~m}$ in Garhwal and Himachal Pradesh where it was previously not endemic (Raina et al. 2009). The implicated vectors are almost certainly Phlebotomus or Sergentomyia species which have ranges restricted by climate. Range shifts of these vector species to 
Aedes aegypti, the principal vector of dengue, has already advanced upward from its historic range.

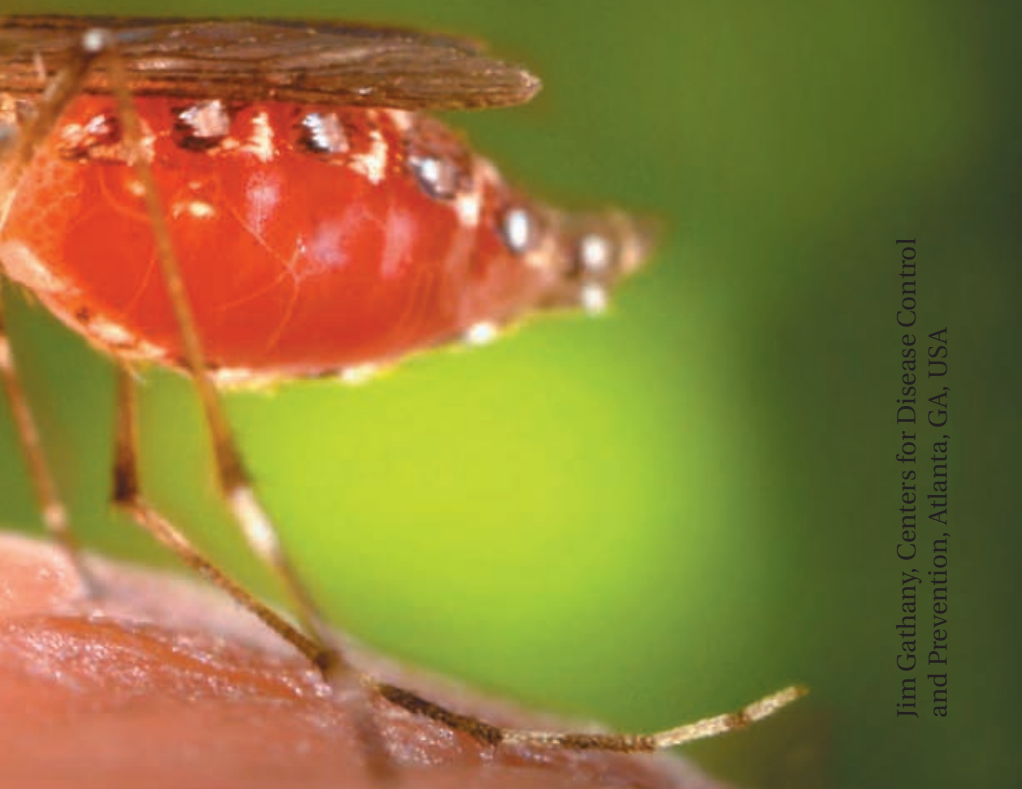

higher elevations may have already been induced by climate change, as suggested by theoretical analyses of the climatic dependencies of these species (Cross et al. 1996, Kuhn et al. 1999, González et al. 2010). Similarly, clinical cases of dengue, as well as larvae of its principal vector, Aedes aegypti, have recently been recorded in the Kumaon hills at elevations higher than previously reported (Shukla and Sharma 1999). In the case of falciparum malaria, there is documentation of its spread into higher altitudes in the Himalayas (Bouma et al. 1996, Bhattacharya et al. 2006). Himalayan populations, with no prior history of exposure to these pathogens, are likely to be more vulnerable than their tropical counterparts.

It is critical that concerted action be taken to prepare for these problems and to investigate if other diseases are also likely to expand their range due to climate change. Unfortunately, except for malaria (the spread of which has been investigated for all of India), there has as yet been no systematic analysis of the emergence of previously absent diseases for any region of the Himalayas. Partly, this reflects the general problem that these other tropical diseases associated with poverty have largely been ignored by recent medical research (Hotez et al. 2007). But it also reflects a lack of quantitative epidemiological and ecological attention to the Himalayas.

Nevertheless, quantitative predictive models of disease risk are necessary prerequisites for any health planning for the region: not only must these models predict the extent of the risk for each specific disease, they must also predict the spatial distribution of this risk. Otherwise, efficient allocation of limited resources to prepare for the future-that is, where and to what extent preventive and ameliorative medical materials and expertise should be distributed-will be impossible. Right now, high resolution risk profiles for disease are not available for a single Himalayan region. Moreover, georeferenced disease incidence data, organized by date, which are necessary for any analysis, have never been collated. Basic data availability for the Himalayas lags behind even tropical Africa.

It is likely that the data availability problems can be rela- tively easily solved, and the necessary analyses performed, for some regions, including the Indian Himalayas and Tibet. However, for other regions, including Bhutan and Nepal, basic epidemiological information is typically lacking for the implicated diseases, partly because these diseases are rare and, therefore, often unrecognized. Even the World Health Organization's regional strategy shows a lack of urgency and entirely ignores the new epidemiological challenges posed by climate change (WHO 2007). But, without immediate and sustained attention to these issues, the challenges will not be surmounted.

\section{Sahotra Sarkar is a professor of biology (Section of Integrative Biology) and philosophy (Department of Philosophy) at University of Texas at Austin, USA.}

\section{References}

Bhattacharya S, C Sharma, RC Dhiman, and AP Mitra. 2006. Climate change and malaria in India. Current Science 90: 369-375

Bouma MJ, C Dye, and HJ van der Kaay. 1996. Falciparum malaria and climate change in the northwest frontier province of Pakistan. American Journal of Tropical Medicine and Hygiene 55: 131-137

Colwell RR. 1996. Global climate and infectious disease: the cholera paradigm. Science 274: 2025-2031

González C, O Wang, S Strutz, C González-Salazar, V SánchezCordero, and S Sarkar. 2010. Climate change and risk of leishmaniasis in North America: predictions from ecological niche models of vector and reservoir species. PLoS Neglected Tropical Diseases 4(1): e585

Hotez PJ, DH Molyneux, A Fenwick, J Kumaresan, S Ehrlich Sachs, JD Sachs, and L Savioli. 2007. Control of neglected tropical diseases. New England Journal of Medicine 357: 1018-1027

Raina S, DM Mahesh, R Kaul, KS Satinder, D Gupta, A Sharma, and S Thakur. 2009. A new focus of visceral leishmaniasis in the Himalayas, India. Journal of Vector-Borne Diseases 46: 303-306

Sharma E, M Chettri, K Tse-ring, AB Shrestha, F Jing, P Mool and M Eriksson. 2009. Climate change impacts and vulnerability in the Eastern Himalayas. Report. Kathmandu: ICIMOD

Shukla RP and SN Sharma. 1999. Aedes aegypti survey of Western Himalayas town of Haldwani, District Nainital, India. Dengue Bulletin 23 (December)

[WHO] World Health Organization. 2007. WHO country cooperation strategy, 2006-2011: Nepal. Kathmandu: WHO 